\title{
CAPÍTULO 03: TECNOLOGIA DIGITAL NA EDUCAÇÃO: O USO DE SMARTPHONES EM SALA DE AULA
}

\author{
CAPÍTULO 03: TECNOLOGÍA DIGITAL EN EDUCACIÓN: EL USO DE \\ SMARTPHONES EN EL AULA
}

\section{CHAPTER 03: DIGITAL TECHNOLOGY IN EDUCATION: THE USE OF SMARTPHONES IN THE CLASSROOM}

\author{
Hêza Ariadne Dos Santos Souza ${ }^{1}$; Luiza Carla Carvalho Siqueira²
}

DOI:https://doi.org/10.31692/978-65-88970-05-8.34-46

\begin{abstract}
RESUMO
A Ciência permite a apreensão do mundo, proporcionando o aparecimento de novas tecnologias que contribuem no desenvolvimento político, social e econômico de uma sociedade. Para isso é necessário repensar a forma tradicional de ensinar, no cenário escolar os dispositivos móveis com conexão sem fio, como os smartphones, trazem novas possibilidades na educação. Pesquisas têm sido desenvolvidas para demonstrar como as tecnologias digitais podem ser utilizadas na escola, a fim de motivar e viabilizar melhores resultados no processo de ensino e aprendizagem. A educação é sem dúvidas uma ferramenta indispensável para a formação de cidadãos, pois é por meio desta que se adquire conhecimento. Diante da necessidade de implementação de ferramentas que visem facilitar a aprendizagem, este estudo tem como objetivo validar o impacto de uma proposta de uso de smartphones em sala de aula no rendimento dos estudantes. Este estudo trata-se de uma pesquisa qualitativa e quantitativa, de natureza aplicada do tipo exploratória, dois questionários foram desenvolvidos e aplicados: um para os discentes e um outro para o docente. Ambos foram aplicados via aplicativo multiplataforma de mensagens. Os resultados obtidos mostram o perfil dos alunos bem como suas afinidades com o uso de dispositivos móveis e seu uso no cotidiano, com diversas finalidades desde o entretenimento até estudo. Ao passo que o professor demostra as vantagens e desvantagens dessas ferramentas quanto ao seu uso, bem como a relação da utilização de tais dispositivos e recursos necessários. Concluindo que é perceptível que os smartphones são um dos elementos que vêm sendo inseridos mais cedo e estão cada vez mais presentes no cotidiano de crianças e adolescentes. Eles apresentam grande potencial de apoio ao ensino e aprendizagem, pela mobilidade e disponibilidade para busca e acesso a informações e materiais multimidiáticos disponíveis na internet, contudo essa alternativa é pouco aproveitada por estudantes e professores nas escolas brasileiras.
\end{abstract}

Palavras-Chave: Educação, ferramenta, smartphones, tecnologia.

\section{RESUMEN}

La ciencia permite la aprehensión del mundo, dando la aparición de nuevas tecnologías que contribuyen al desarrollo político, social y económico de una sociedad. Para ello, es necesario repensar la forma tradicional de enseñar, en el escenario escolar dado por los dispositivos móviles con conexión inalámbrica, como los teléfonos inteligentes, que traen nuevas posibilidades en la educación. Se ha desarrollado una investigación para demostrar cómo se pueden utilizar las tecnologías digitales en la escuela, con el fin de motivar y permitir mejores resultados en el proceso de enseñanza y aprendizaje. La educación es sin duda una herramienta indispensable para la formación de los ciudadanos, ya que a través de ella se adquieren conocimientos. Dada la necesidad de implementar herramientas que tengan como objetivo facilitar el aprendizaje, este estudio tiene como objetivo validar el impacto de una propuesta de uso de teléfonos inteligentes en el aula sobre el desempeño de los estudiantes. Este estudio es una investigación cualitativa y cuantitativa, de carácter exploratorio aplicado, se desarrollaron y

\footnotetext{
${ }^{1}$ Licenciatura em Ciências Biológicas, Faculdade De Ciências Humanas do Sertão Central (FACHUSC), hezasouza@gmail.com

${ }^{2}$ Mestra em Inovação em Tecnologias Educacionais, Universidade Federal do Rio Grande do Norte (UFRN), lukrvalho@gmail.com
} 
aplicaron dos cuestionarios: uno para los estudiantes y otro para el docente. Ambos se aplicaron a través de una aplicación de mensajería multiplataforma. Los resultados obtenidos muestran el perfil de los estudiantes, así como sus afinidades con el uso de dispositivos móviles y su uso en la vida cotidiana, con diferentes fines desde el entretenimiento hasta el estudio. Mientras que el docente demuestra las ventajas y desventajas de estas herramientas en cuanto a su uso, así como su relación con el uso de dichos dispositivos y recursos necesarios. En conclusión, llama la atención que los teléfonos inteligentes son uno de los elementos que se han insertado antes y están cada vez más presentes en la vida cotidiana de los niños y adolescentes. Tienen un gran potencial para apoyar la enseñanza y el aprendizaje, debido a su movilidad y disponibilidad para buscar y acceder a información y materiales multimedia disponibles en Internet, sin embargo, esta alternativa es poco utilizada por estudiantes y profesores en las escuelas brasileñas.

Palabras Clave: Educación, herramientas, teléfonos inteligentes, tecnología.

\section{ABSTRACT}

Science allows the apprehension of the world, providing the appearance of new technologies that contribute to the political, social and economic development of a society. For this, it is necessary to rethink the traditional way of teaching, in the school scenario given by mobile devices with wireless connection, such as smartphones, bring new possibilities in education. Research has been developed to demonstrate how digital technologies can be used at school, in order to motivate and enable better results in the teaching and learning process. Education is undoubtedly an indispensable tool for the formation of citizens, as it is through this that knowledge is acquired. Given the need to implement tools that aim to facilitate learning, this study aims to validate the impact of a proposal to use smartphones in the classroom on student performance. This study is a qualitative and quantitative research, of an exploratory applied nature, two questionnaires were developed and applied: one for the students and another for the teacher. Both were applied via a multiplatform messaging application. The results obtained show the profile of the students as well as their affinities with the use of mobile devices and their use in everyday life, with different purposes from entertainment to study purposes. While the teacher demonstrates the advantages and disadvantages of these tools in terms of their use, as well as their relation to the use of such devices and necessary resources. In conclusion, it is noticeable that smartphones are one of the elements that have been inserted earlier and are increasingly present in the daily lives of children and adolescents. They have great potential to support teaching and learning, due to their mobility and availability for searching and accessing information and multimedia materials available on the internet, however this alternative is little used by students and teachers in Brazilian schools.

Keywords: Education, tool, smartphones, technology.

\section{INTRODUÇÃO}

A Ciência permite a apreensão do mundo, proporcionando o aparecimento de novas tecnologias que contribuem no desenvolvimento político, social e econômico de uma sociedade. Atualmente, no campo da educação, a ciência e a tecnologia recebem uma nova definição na formação do indivíduo. O ensino de Ciências tem por finalidade transmitir os conhecimentos científicos, que consentirão ao cidadão tomar decisões de interesse particular e grupal, dentro da sua ética (KRASILCHIK, 2008).

Para isso é necessário repensar a forma tradicional de ensinar, onde memorização são tidas como única forma de aprender, pois essa metodologia rotineira, não considera a construção do conhecimento através do discente, fazendo com que os conceitos 
pareçam desinteressantes e distantes da sua realidade (MENEGAIS; FAGUNDES; SAUER, 2015).

Os docentes são conscientes de que não existe uma didática perfeita o que existem são métodos que funcionam melhor ou pior e de acordo com o público alvo que se tem. A utilização de ferramentas metodológicas diversificadas que agucem os diferentes sentidos e que coloquem o sujeito da aprendizagem em contato direto com o objeto de estudo pode promover a construção do conhecimento em Ciências (ANDRÉ, 2014).

No cenário escolar dado pelos dispositivos móveis com conexão sem fio, como os smartphones, trazem novas possibilidades na educação, como o prolongamento de práticas além dos limites físicos do ambiente escolar, além de descentralizá-la no que se refere ao professor como única fonte de acesso ao conhecimento. Essas características ampliam, entre outras possibilidades, o desenvolvimento da mobile learning, que é uma modalidade educativa em que processos de aprendizagem ocorrem com o uso de dispositivos móveis, conectados a redes de comunicação sem fio. (SACCOL, SCHLEMMER e BARBOSA, 2011).

Pesquisas têm sido desenvolvidas para demonstrar como as tecnologias digitais podem ser utilizadas na escola, a fim de motivar e viabilizar melhores resultados no processo de ensino e aprendizagem. As tecnologias estão presentes no cotidiano dos jovens e vem construindo um espaço dentro das escolas com o uso de smartphones. Os adolescentes já as dominam e se faz necessário que os professores entrem no ritmo. (ALMEIDA; LOPES, 2014)

A educação é sem dúvidas uma ferramenta indispensável para a formação de cidadãos, pois é por meio desta que se adquire conhecimento. Diante da necessidade de implementação de ferramentas que visem facilitar a aprendizagem, este estudo tem como objetivo validar o impacto de uma proposta de uso de smartphones em sala de aula no rendimento dos estudantes.

\section{FUNDAMENTAÇÃO TEÓRICA}

Em conformidade com as Diretrizes para as Políticas de Aprendizagem Móvel, facilidade de acesso aos dispositivos e a crescente difusão do uso na sociedade faz com que cada vez mais pessoas tenham, ao menos, um dispositivo ao seu dispor e saibam como utilizálo. Os dispositivos móveis, como os smartphones, potencialmente são ferramentas importantes para contribuir com a melhoria e ampliação da aprendizagem. (UNESCO, 2014)

Atualmente a maior parte dos discentes está habituada ao mundo digital, com o uso diário de dispositivos eletrônicos como tablets, smartphones, e notebooks, tornando-se imprescindível a inovação das práticas pedagógicas com o intuito de acompanhar e conquistar 
este público acostumado a multifuncionalidade e a diferentes estímulos. (RUCATTI; SOUZA ABREU, 2015)

Conforme Lemos (2010), as tecnologias móveis estão modificando os relacionamentos entre as pessoas e os ambientes urbanos em que vivem, inovanado diversas formas de mobilidade. Consequentemente, a sociedade vai ser tornando cada vez mais ubíqua, pois essas tecnologias permitem que esses espaços ser tornem ambientes de interconexão, envolvendo o usuário em plena mobilidade, envolvendo objetos e pessoas. A probabilidade do individuo carregar consigo o motivo de estudo, ou conseguir acessá-lo de qualquer lugar, potencializa o uso de dispositivos móveis na educação.

Diante das possibilidades do uso de smartphones na educação, percebe-se a necessidade de criar e adaptar práticas de ensino a este novo ambiente em que educação e tecnologia se interconectam. Moraes, Santos e Oliveira (2014) explicam que o principal desafio é o de encontrar caminhos para utilizar tais ferramentas no contexto educativo a fim de possibilitar que os discentes aprendam a trabalhar de forma colaborativa, tornando-se protagonistas, acompanhados pelos professores que vão atuar como mediadores no processo de construção da aprendizagem.

A apresentação de novas informações, inclusive utilizando recursos tecnológicos, pode viabilizar a aprendizagem. Neste contexto, relacionar o conteúdo com aspectos conhecidos pelos estudantes, utilizar linguagem apropriada à faixa etária e selecionar materiais potencialmente significativos representam condições a serem viabilizadas na ação docente. As tecnologias digitais podem se configurar como ferramentas potencialmente significativas ao mobilizar a atenção e a motivação dos aprendizes e auxiliar no processo de incorporação de novos conhecimentos (PADILHA; SUTIL; ALMEIDA PINTO, 2014).

A simples inserção dos smartphones não significa que haverá mudanças na maneira de se promover a educação. Não se trata de reproduzir as mesmas atividades que são realizadas com lápis e papel, esse tipo de proposta pode operacionalizar os sujeitos, propiciando distribuição de cliques sem significação na tela, caracterizando um uso mecânico que não reflete uma interação crítica com o contexto digital. (BISPO FILHO; MACIEL; SEPINI; ALONSO, 2013).

A presença diária das tecnologias digitais no cotidiano de jovens e adultos visa facilitar a comunicação e resolução de simples questionamentos. Além de ser uma potencial ferramenta educativa para ser utilizada no processo de ensino e aprendizagem do aluno. Percebe-se uma busca dos discentes por aulas que se utilizem de métodos e ferramentas inovadoras. Contudo, muitos professores não se sentem seguros ou preparados com este modelo de proposta. Há 
muitos aplicativos didáticos disponíveis, mas as escolas não utilizam esses recursos, por isso, muitas delas não conseguem conter o uso inadaptado do celular durante as aulas. (DA SILVA, 2017).

Alguns professores mantêm suas práticas centradas nos métodos mais tradicionais e/ou descartam o uso de ferramentas tecnológicas por falta de contato, interesse ou de políticas de formação continuada que promovam a integração destes meios tecnológicos à prática docente. As tecnologias precisam ser compreendidas e incorporadas, para que possam surtir efeito e trazer as alterações necessárias no processo educativo. É indispensável saber desenvolver, elaborar e planejar uma prática educativa de forma pedagogicamente correta, para a tecnologia escolhida, sendo importante um preparo. $\mathrm{O}$ atual perfil do discente necessita compreender para que e o por que estudar determinados assuntos abordados nas aulas. É trabalhoso, consequentemente, cativar a atenção do aluno em aulas realizadas apenas pelo conjunto quadro, pincel, livro e professor. Sendo possível notar a insatisfação dos alunos em relação às aulas consideradas tradicionais, sem a incorporação de qualquer tecnologia. (KENSKI, 2007)

\section{METODOLOGIA}

Este estudo trata-se de uma pesquisa qualitativa e quantitativa, de natureza aplicada do tipo exploratória e foi realizado no município de Salgueiro, localizado no Sertão Central, no estado de Pernambuco (Figura 01). A pesquisa foi desenvolvida com uma turma do $3^{\circ}$ ano do Ensino Médio, da Escola de Referência em Ensino Médio Professor Urbano Gomes de Sá (Figura 02), localizada na área urbana, abrangendo um total de 35 estudantes e um docente responsável pela disciplina de Biologia.

Figura 01- Mapa de Localização do municipio de Salgueiro, localizado no Sertão Central, Pernambuco, Brasil.

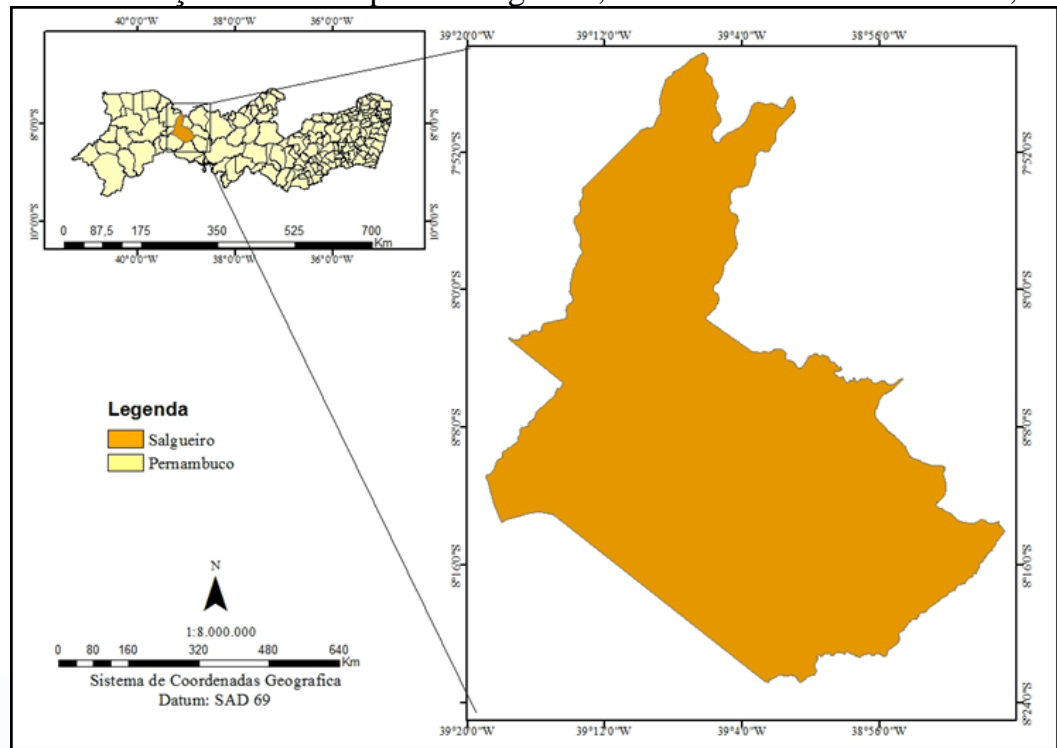

Fonte: Researchgate, 2017

[38] 
Figura 02 - Fachada da Escola De Referência em Ensino Medio Professor Ubarno Gomes De Sá, localizada no municipiod de Salgueiro.

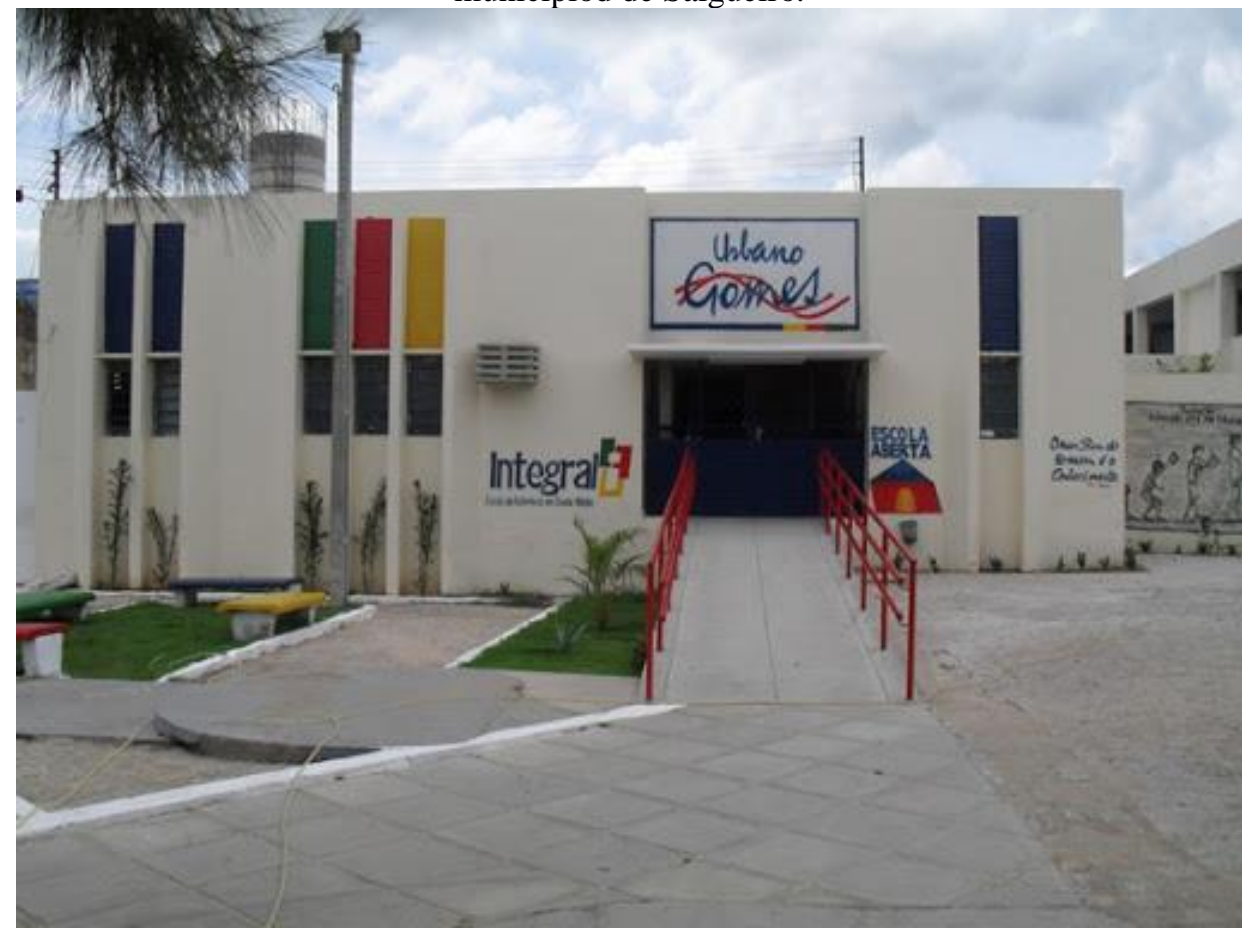

Fonte: Própria, 2020

Dois questionários foram desenvolvidos e aplicados: um para os discentes e um outro para o docente. Ambos foram aplicados via aplicativo multiplataforma de mensagens. Dentro do questionário do discente foi realizado um levantamento sobre o perfil socioeconômico, também foram incluídas perguntas abertas que buscavam identificar as tecnologias utilizadas (tipos e finalidade da utilização).

O questionário do docente continha perguntas sobre sua área de formação e disciplinas de atuação, em relação ao uso de dispositivos móveis foram questionados como tais ferramentas eram utilizadas pelo professor, se havia algum planejamento para o uso em ação pedagógica. Também foi questionado a respeito das dificuldades para a utilização desses recursos e se durante ou pós a formação o docente havia participado de alguma capacitação ou de ações que promoviam a integração de tecnologias digitais a prática docente. Além disso levantou-se as vantagens e desvantagens, bem como a importância do uso dessas tecnologias a partir do ponto de vista do professor.

A partir dos dados obtidos e posteriormente a tabulação desses, foram levantadas pesquisas bibliográficas a fim de compreender se a proposta de legitimar o uso de smartphone em sala de aula, resulta em um aspecto positivo para o aprendizado dos alunos, e se existem pontos negativos a respeito de tal uso. Além de verificar os empecilhos a tal proposta e a percepção do professor quanto ao uso do dispositivo como uma ferramenta. 


\section{RESULTADOS E DISCUSSÃO}

Através da tabulação de dados foi possível identificar que os alunos possuíam idade entre 17 e 19 anos, sendo 62,9\% do sexo feminino e 37,1\% masculino. Quando questionados sobre a renda familiar, 54,3\% responderam possuir renda mensal inferior a um salário mínimo; e $45,7 \%$ renda mensal entre um ou dois salários mínimos. A respeito de possuírem algum dispositivo eletrônico, todos os discentes afirmaram ter ao menos um smartphone. De acordo com as Diretrizes para as Políticas de Aprendizagem Móvel (UNESCO, 2014), a facilidade de acesso aos dispositivos e a crescente disseminação do uso na sociedade faz com que cada vez mais pessoas tenham, ao menos, um dispositivo ao seu dispor.

Em relação a frequência em que os alunos acessam à internet durante o dia (Figura 03), $42,9 \%$ responderam que fazem o uso da mesma por mais de quatro horas, $20 \%$ entre quatro e três horas, $14,2 \%$ entre três e duas horas e $14,2 \%$ entre duas e uma hora e $8,7 \%$ até uma hora. Ficando evidente que todos os alunos utilizam a internet por no mínimo uma hora por dia. Sobre o local onde fazem o acesso, 68,5\% dos discentes responderam que usam em casa, 25,8\% no próprio smartphone e $5,7 \%$ na escola.

Quando questionados sobre possuírem algum perfil em alguma rede social, 88,7\% responderam que possuem conta no Instagram, no Facebook e em outras plataformas, enquanto que apenas 11,3\% não possui conta em nenhuma rede social. Groenwald e Homa (2014) afirmam que a maioria dos estudantes fazem uso das Tecnologias, principalmente as redes sociais, como recurso para comunicação e diversão, não reconhecendo o potencial destas ferramentas como ferramentas didáticas de apoio a aprendizagem.

Figura 03 - Frequência em Horas diárias em que os discentes permanecem conectados à internet durante o dia.

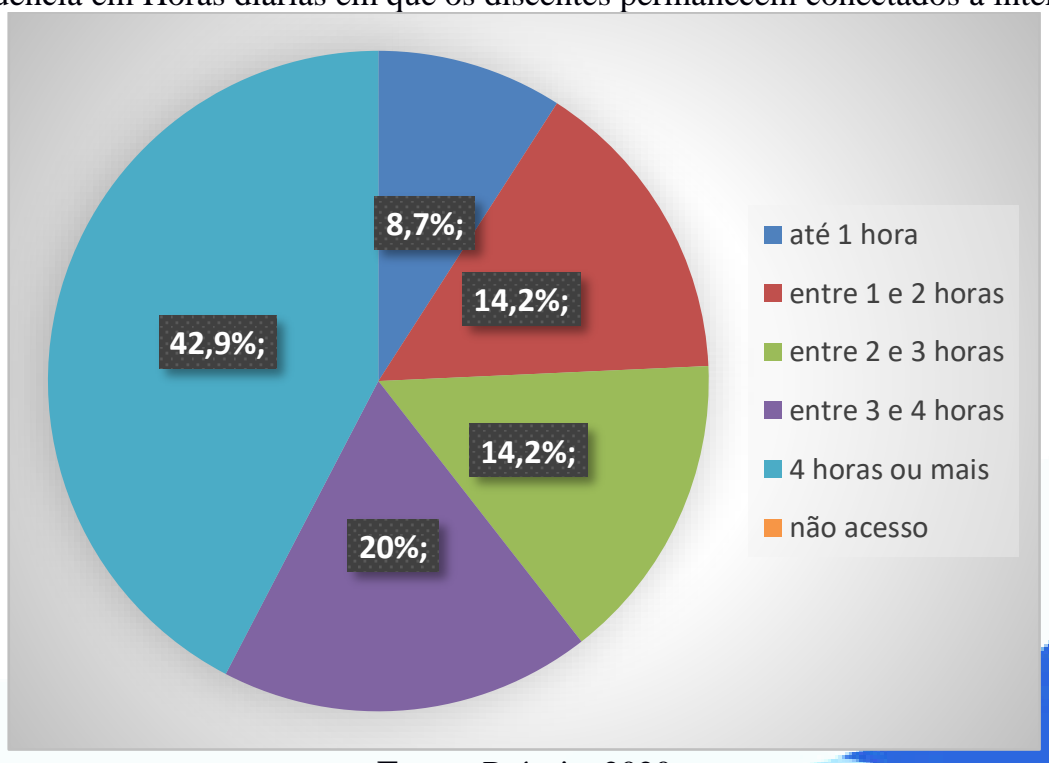

Fonte: Própria, 2020

[40] 
Sobre a utilização de algum aplicativo para estudo, 71,4\% dos discentes responderam que utilizam alguma plataforma para estudo, entre as plataformas utilizadas foram os mais citados YouTube e Google. Em relação ao YouTube, 97,1\% dos estudantes indicaram que utilizam a plataforma, sendo que 57,1\% fazem o acesso diariamente, $28,5 \%$ semanalmente e 14,4\% raramente (Figura 04). Nos dados obtidos sobre a finalidade, foi observado que todos os estudantes utilizam o YouTube como uma forma de entretenimento, enquanto que apenas 45,7\% o utilizam para fins de estudo. É perceptível o crescimento de visualizações de vídeos, os vídeos transmitem um contexto de entretenimento tornando-se atrativo para os alunos. Diante dessa ótica é crescente a busca por vídeo aulas e a disponibilização e a criação de canais específicos com fins educacionais. (SILVA, PEREIRA, ARROIO, 2017)

Sobre a plataforma do Google $94,2 \%$ dos alunos a utilizam, desses $57,1 \%$ dos discentes usufruem da plataforma para realizar pesquisas com a finalidade de aprendizado, enquanto que o restante usa na intenção de recreação. Todos os estudantes acessam WhatsApp para comunicação, destes $85,7 \%$ usam diariamente, $8,6 \%$ semanalmente e 5,7\% raramente. (Figura 05). Há inúmeras maneiras de utilizar o celular e a plataforma do WhatsApp, podendo ser um importante suporte, como ferramenta pedagógica se tornando viável para o processo de ensinoaprendizagem, na medida em que possibilita a ação comunicativa entre os discentes, sendo capaz de ser utilizado para desenvolvimento de atividades de leitura em sala de aula. (SANTOS, 2013)

Figura 04 - Frequência em relação ao tempo dedicado ao acesso ao Youtube pelos discentes.

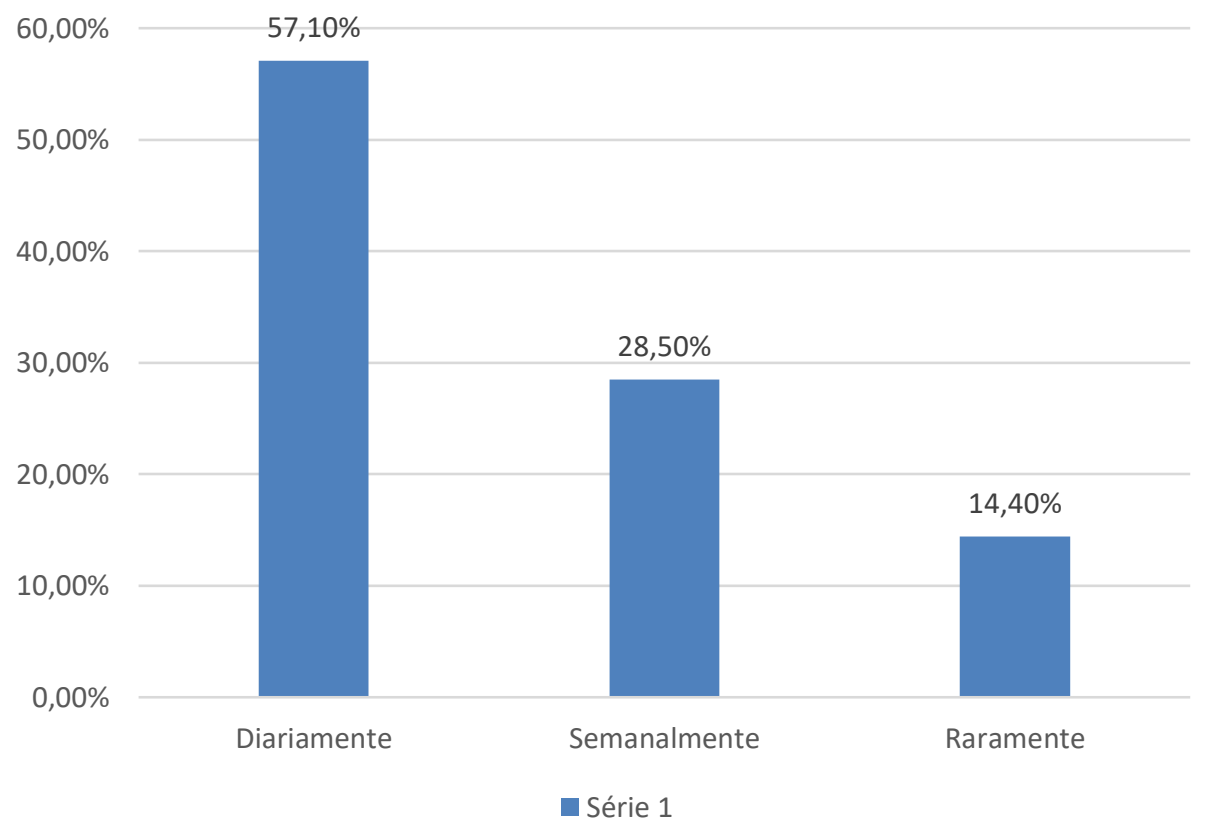

Fonte: Própria, 2020 
Figura 05 - Frequência referente ao tempo de acesso ao WhatsApp feito pelos discentes.

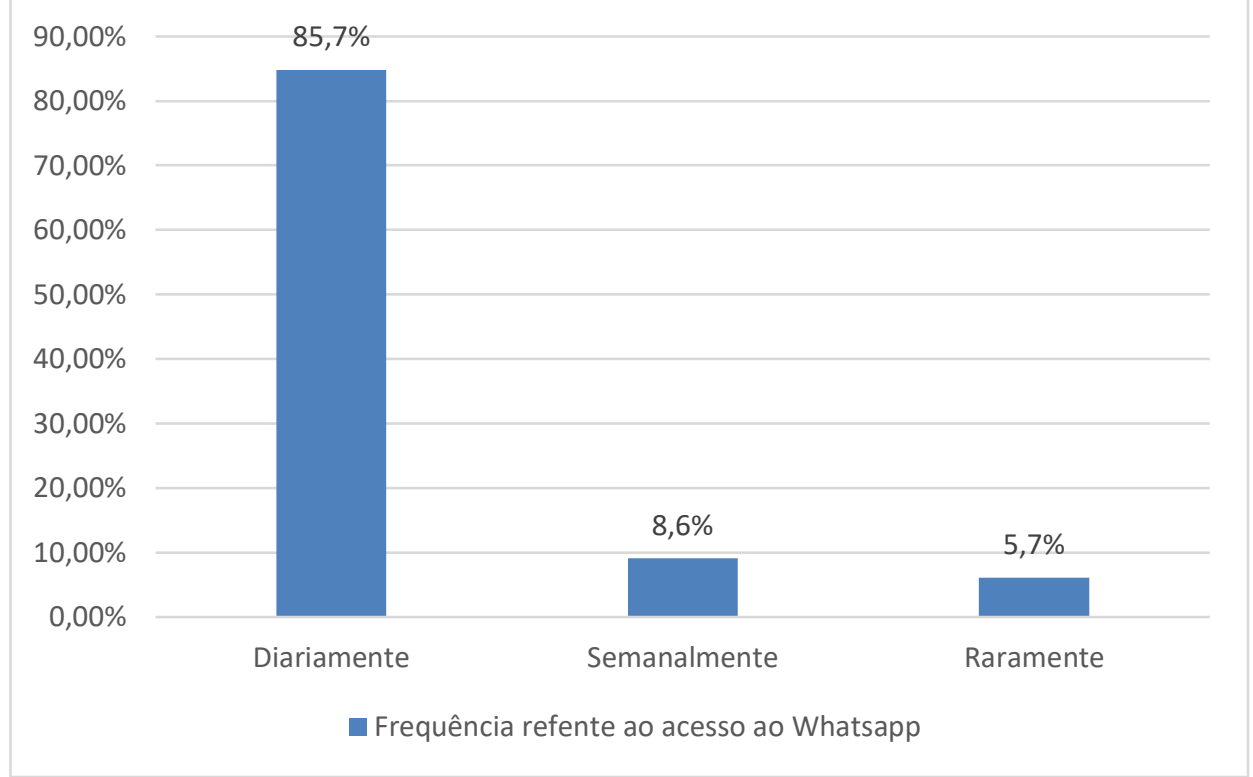

Fonte: Própria, 2020

Em relação a possível conciliação entre estudos e uso de smartphones 54,2\% dos discentes acreditam que pode acontecer, com organização e planejamento, mas que é essencial um baseamento teórico do docente, sendo utilizado somente como uma ferramenta de apoio. Os discentes que discordaram, se justificaram pelas distrações que o dispositivo poderia oferecer. Para Pereira, Tarcia e Sigulem (2012), a utilização de dispositivos móveis pode servir para motivar os discentes e tornar o método ensino e aprendizagem inovador, com mais qualidade e didático.

Quando solicitados exemplos de como tornar a aula mais atrativa e dinâmica (Figura 06), 31,5\% responderam que as aulas deveriam ser mais divertidas e descontraídas, com brincadeiras ou algum método que prenda a atenção dos discentes; 25,7\% afirmaram a necessidade de aulas práticas; $20 \%$ não souberam responder; e 22,8\% citaram que as aulas poderiam utilizar algum dispositivo móvel, como tablets, notebooks e smartphones. Muitos estudos têm apontado que o celular pode ser considerado como um recurso didático, necessitando, portanto, de uma interferência apropriada por parte dos educadores, capaz de sensibilizar o discente a compreender sua utilização sobre essa perspectiva, no contexto da sala de aula (DOS SANTOS; SANTOS, 2015). 
Figura 06 - Percepção dos alunos sobre como tornar a aula mais atrativa

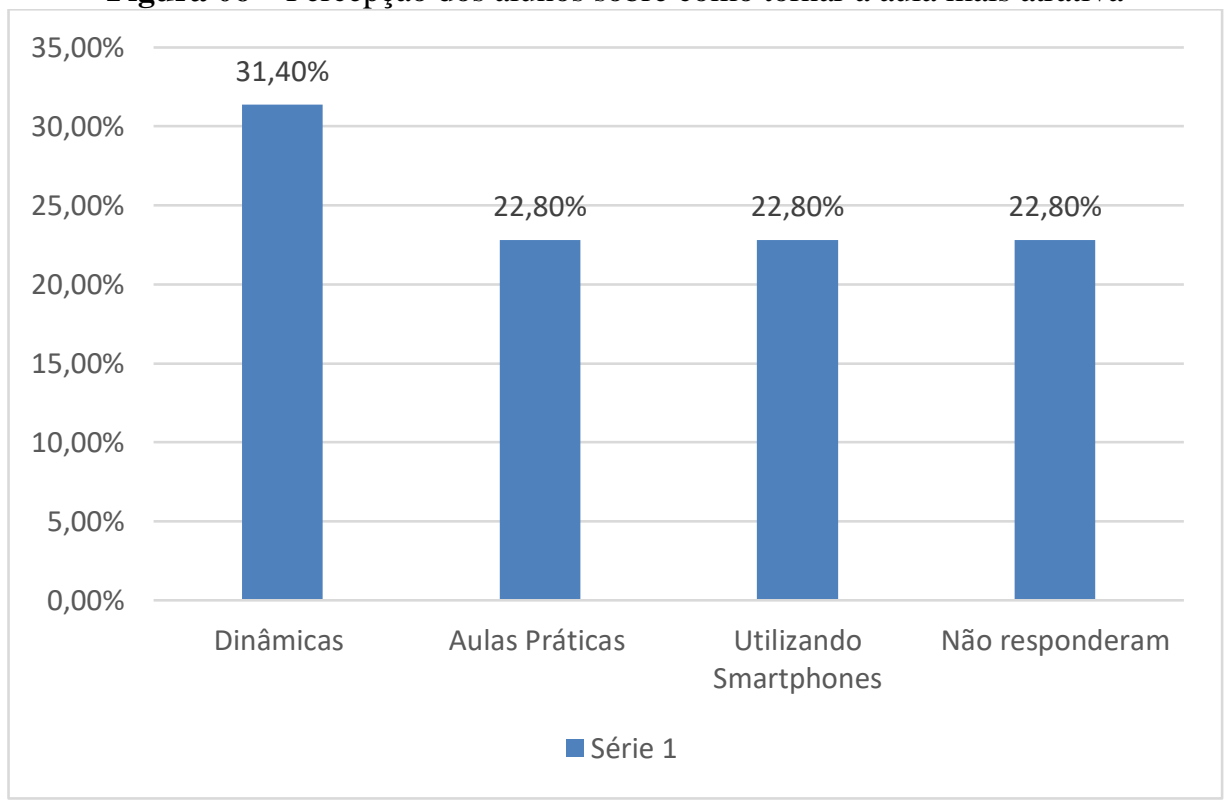

Fonte: Própria, 2020

Barbosa e Bassani (2013) comentam que com os recursos que a internet proporciona, é possível produzir processos educativos, enfatizando a elaboração e a coletivização do conhecimento. Isso é possível devido a utilização de diferenciadas ferramentas e de meios de comunicação que possibilitam a interatividade e o trabalho cooperativo e colaborativo. Relacionar as tecnologias ao processo de ensino e aprendizagem do sujeito tende a ajudar na edificação do conhecimento, uma vez que as tecnologias digitais estão cada vez mais presentes em todas as esferas da sociedade atual.

Frente ao questionário do docente, a respeito da formação foi visualizado que o professor é formado em ciências biológicas, com 13 anos de tempo de exercício, atuando nas disciplinas de Biologia e Química. Sobre possuir algum dispositivo móvel, o docente disse possuir um smartphone, Notebook, Tablet e Computador. Questionado sobre o que costuma utilizar como recurso tecnológico para planejamento ou execução para ações pedagógicas, o professor afirmou que utiliza o computador e o celular para pesquisas, elaboração de atividades e ministração de aulas.

Em relação as dificuldades para a utilização desses recursos, o docente citou a ausência de uma internet de qualidade. Sobre a participação de disciplinas, durante a formação inicial, ou de ações que visassem promover a integração das tecnologias digitais á pratica docente, o professor respondeu que durante sua formação não houve investimento na área por parte das instituições envolvidas, sendo necessário uma iniciativa própria. Já em relação a participação de formações continuadas o docente afirmou ter participado de alguns cursos.

Segundo Santana \& Medeiros (2008), a capacitação dos professores é essencial. A 
ausência desta capacitação, transformam os recursos tecnológicos em adornos sem significados mediacionais para discentes e docentes. Sendo o papel do docente extremamente importante nos projetos de inovações, pois a qualidade de um espaço tecnológico de ensino depende de como é investigado didaticamente.

Sobre as vantagens e desvantagens que os recursos tecnológicos podem trazer, o docente apontou como ponto positivo o acesso rápido a informações e como ponto negativo as falhas que podem haver quanto ao uso em sala de aula, podendo deixar em algumas situações sem opções de saída de emergência e assim atrapalhar o andamento da aula.

Quanto a importância do uso de tais recursos, o professor afirmou ser necessário e ressaltou a facilidade com que a tecnologia permite o acesso à informação. Porto e Marcola (2004), defendem que para um melhor aproveitamento dos recursos tecnológicos é preciso que o docente conheça os suportes midiáticos e todas as probabilidades educacionais e interativas das redes e espaços virtuais para aproveitá-las nas mais variadas situações e diferentes realidades educacionais.

\section{CONCLUSÕES}

Frente aos avanços tecnológicos e uma sociedade cada vez mais informatizada e midiatizada, a educação ainda não tem conseguido integrar os elementos da cultura digital aos espaços escolares e processos educativos. Os motivos variam desde questões de infraestrutura, indisponibilidade de equipamentos, falta de recursos financeiros e políticas de formação (inicial e continuada) que favoreçam o uso didático e pedagógico de ferramentas tecnológicas digitais na sala de aula das escolas.

Os smartphones são um dos elementos que vêm sendo inseridos mais cedo e estão cada vez mais presentes no cotidiano de crianças e adolescentes. Eles apresentam grande potencial de apoio ao ensino e aprendizagem, pela mobilidade e disponibilidade para busca e acesso à informações e materiais multimidiáticos disponíveis na internet, contudo essa alternativa é pouco aproveitada por estudantes e professores nas escolas brasileiras.

Há muita dificuldade por parte dos professores para planejar e combinar as aulas e elaborar estratégias que favoreçam ao aluno aprender com este recurso tecnológico. Contudo os smartphones estão cada vez mais presentes na sala de aula, por isso devem ser utilizados com a finalidade de contribuir com o desenvolvimento dos conteúdos disciplinares.

Uma vez que os alunos estão imersos ao mundo da tecnologia, utilizando-se desses meios não somente para comunicação e entretenimento, mas também como uma ferramenta 
auxiliar nos estudos. Provando que o smartphone pode ser um método utilizado em sala de aula de forma que contribua com o desenvolvimento da aprendizagem e aprimoramento do ensino por parte do docente.

Porém é necessário que haja um planejamento, e construção de um roteiro onde o dispositivo móvel não seja apenas um coadjuvante. Sendo necessário mudar o ponto de vista que os professores possuem, onde continuam apontando que as facilidades dessas ferramentas se referem exclusivamente à apresentação do conteúdo e não à potencialização da aprendizagem pela diversidade de linguagens e espaços interativos que o smartphone possibilita.

\section{REFERÊNCIAS}

ALMEIDA, C.M.M; LOPES, P.T.C. Prática educativa usando a plataforma SIENA para o ensino de Ecologia no 6 ano do ensino fundamental. Revista Novas Tecnologias na Educação, v.12, n.1, p.1-10, 2014.

ANDRÉ, B. P. O lugar da didática no ambiente virtual de aprendizagem. Revista Brasileira de Ensino de Ciência e Tecnologia, v.7, n.3, 63-77, 2014, RJ.

BARBOSA, D. N. F.; BASSANI, P. B. S. Em direção a uma aprendizagem mais lúdica, significativa e participativa: experiências com o uso de jogos educacionais, tecnologias móveis e comunidade virtual com sujeitos em tratamento oncológico. Revista Novas Tecnologias na Educação, v.11, n.1, p.1-10, 2013.

BISPO FILHO, D. O; MACIEL, M. D.; SEPINI, R. P.; ALONSO, Á. V. Alfabetização científica sob o enfoque da ciência, tecnologia e sociedade: implicações para a formação inicial e continuada de professores. Revista Electrónica de Enseñanza de las Ciencias, v.12, n.2, p.313-333, 2013.

DA SILVA, J. M. Novas tecnologias em sala de aula. Revista ciencia, salud, educación y economia n. 11, p. 32, 2017.

DOS SANTOS, J. O.; SANTOS, R. M. S. O uso do celular como ferramenta de aprendizagem. Revista Brasileira de Educação e Saúde, v. 4, n. 4, p. 1-6, 2015. Disponível em: http://gvaa.com.br/revista/index.php/REBES/article/view/3108/2596

GROENWALD, C. L. O.; HOMA, A. I. R. Ambiente virtual de aprendizagem do Programa de Pós-Graduação em Ensino de Ciências e Matemática da ULBRA. Acta Scientiae, v. 16, 2014.

KRASILCHIK, M. Prática de ensino em Biologia. 4. Ed. São Paulo : Harper \&Row, 2008

KENSKI, V. M. Educação e tecnologias: o novo ritmo da informação. Campinas, SP: Papirus, 2007.

LEMOS, A. Derivas: Cartografia do Ciberespaço. In: Cibercultura e Mobilidade: a era da conexão. Annablume, São Paulo, 2004. 
MENEGAIS, D. A. F.N.; FAGUNDES, L. C.; SAUER, L. Z. A análise do impacto da integração da plataforma KHAN ACADEMY na prática docente de professores de matemática. Revista Novas Tecnologias na Educação, v.13, n.1, p.1-11, 2015.

MORAES, D. A. F.; SANTOS, A. R. J.; OLIVEIRA, D. E. M. B. Aprendizagem colaborativa na educação superior: desvelando possibilidades com o uso da ferramenta Google Drive.

Revista Tecnologias na Educação, v.6, n.10, p.1-1, 2014.

PADILHA, A. S. C.; SUTIL, N.; ALMEIDA PINTO, Â. E. Tecnologias de Informação e Comunicação e aprendizagem significativa: perspectivas de professores de Ciências. Revista Tecnologias na Educação, v.6, n.11, p.1-12, 2014.

PEREIRA, T. A.; TARCIA, R. M. L.; SIGULEM, D. Tecnologias móveis: aliadas na educação e na saúde. XIII CONGRESSO BRASILEIRO EM INFORMÁTICA EM SAÚDE. Anais.... Curitiba, 2012.

PORTO, T.M.E. \& MARCOLA, Valdinei. A formação do professor e as tecnologias de informática na Universidade Federal de Pelotas. CINTED-URFG Novas Tecnologias na Educação, vol. 2, nº 1, Março, 2004. Texto disponível em: < http://www.cinted.ufrgs.br/renote/mar2004/artigos/33-aformacao_professor.pdf $>$. Acessado em 03 de setembro de 2010.

RUCATTI, L. G.; SOUZA ABREU, C. BAAS: Uma plataforma online para apoio à leitura e aprendizagem. Revista Novas Tecnologias na Educação, v.13, n.1, p.1-10, 2015.

SACCOL, A.; SCHLEMMER, E.; BARBOSA, J. M-learning e u-learning: novas perspectivas das aprendizagens móvel e ubíqua. São Paulo: Pearson Prentice Hall, 2011.

SANTANA, J.C. de. \& MEDEIROS, Quitéria. A utilização do uso de novas tecnologias no ensino de ciências. Texto disponível em: <

http://www.senept.cefetmg.br/galerias/Arquivos_senept/anais/terca_tema1/TerxaTema1Artig o14.pdf>. Acessado em 10/07/2010.

SANTOS, Sandra Virgínia Correia de Andrade. O uso do celular nas práticas de letramento. In: vi fórum identidades e alteridades. In II Congresso Nacional Educação E Diversidade, 2013, Itabaiana/SE. Anais. UFS/Itabaiana/SE Brasil. p. 1-10.

SILVA, M. G.; BATISTA, C. F. Metodologia de avaliação: análise da qualidade de aplicativos educacionais para matemática no ensino médio. Revista Novas Tecnologias na Educação, v.13, n.1, p.1-10, 2015

SILVA, M. J., PEREIRA, M. V., ARROIO, A. O papel do Youtube no ensino de ciências para estudantes no ensino médio. Revista de Educação, Ciências e Matemática, v.7, n. 2. p. $35-55$, maio/ago, 2017.

UNESCO. Policy Guidelines for Mobile Learning Disponível em: http://unesdoc.unesco.org/images/0021/002196/219641E.pdf. Aceso em: 10 de janeiro de 2014 